\title{
The Scope of Psychotherapy Integration: Introduction to a Special Issue
}

\author{
Paul L. Wachtel ${ }^{1}$. Judith P. Siegel ${ }^{3}$. Judith C. Baer ${ }^{2}$
}

Published online: 24 July 2020

(c) Springer Science+Business Media, LLC, part of Springer Nature 2020

This special issue of the journal is intended to introduce readers to developments in the field of psychotherapy integration and to the Society for the Exploration of Psychotherapy Integration (SEPI). All of the papers in this issue were based on presentations at recent SEPI meetings in New York and in Lisbon.

SEPI is an organization devoted to a wide range of efforts to put together the differing strengths of different approaches to therapy and to enable therapists both to learn approaches other than their own original or core approach and to examine how these differing perspectives and methods can be combined in a coherent fashion. It is also devoted to bringing together clinicians and researchers so that clinical work is better informed by the latest research findings and research is enabled to be more clinically relevant and to address in more sophisticated and realistic ways the actual challenges clinicians face. These various elements of SEPI's mission are well illustrated in the papers that follow.

An influential early framing of the different broad approaches to the integration of differing clinical orientations or modalities was offered by Arkowitz $(1984,1997)$. The least elaborated of these approaches is that of technical eclecticism. This is primarily an empirical, non-conceptual approach in which the aim is to examine the literature broadly to find "what works," without much regard for what theoretical orientation it derives from. Proponents of the technically eclectic approach to integration (e.g., Lazarus 1989; Lazarus and Lazarus 2019; Beutler 1983; Consoli and

Paul L. Wachtel

paul.wachtel@gmail.com

1 Doctoral Program in Clinical Psychology, City College of New York, 138th Street and Convent Avenue, New York, NY 10031, USA

2 Rutgers, The State University of New Jersey, 536 George St., New Brunswick, NJ 08901, USA

3 Silver School of Social Work at New York University, New York, NY, USA
Beutler 2019) generally emphasize techniques, not theories and can at times be almost militantly atheoretical. They advocate that we "cull effective techniques from many orientations without subscribing to the theories that spawned them." (Lazarus and Lazarus 2019, p. 125) and that there is a need for "evidence-based therapies that facilitate human change by eschewing the broad definitions of treatment type and patient diagnosis in favor of matching narrower treatment interventions to specific problems, patients, and populations." (Consoli and Beutler 2019, p. 141).

A more conceptual approach to integration is evident in the common factors strategy. This approach to integration builds upon the frequent and robust finding that in the vast majority of cases, the empirical evidence indicates that the various competing theories and orientations get roughly the same results for most patients. This very reliable finding has suggested to proponents of the common factors approach that the same basic underlying therapeutic processes are at work in each of the nominally different approaches and that, in essence, they each deliver the active ingredients of therapy in a different package. The common factors approach can be traced back to the prescient work of Saul Rosenzweig (1936), who also was the first to describe this equivalent effectiveness of different therapeutic approaches as the Dodo bird verdict (after the Dodo in Alice in Wonderland who said "Everybody has won and all must have prizes"). This perspective on therapy was given an enormous boost by the publication of Jerome Frank's (1961) Persuasion and Healing, followed by several influential further editions over the years. Frank was one of the earliest empirical investigators of psychotherapy outcome and he both described the surprising finding that the results of purportedly different and competing approaches in fact were quite similar and outlined a theoretical understanding of the common factors that accounted for these similar results. Frank's analysis centered on four major sources of influence: (1) a therapeutic relationship that provides the patient with confidence that his or her therapist is both competent and caring; (2) a socially 
sanctioned setting. Here Frank remains in the vanguard in highlighting a view still not sufficiently appreciated - that psychotherapy is a socially and culturally contextual event, and that different kinds of interventions and settings are appropriate in different societies and cultures; (3) a persuasive therapeutic rationale. Here, Frank highlights that the rationale must be persuasive, not that it needs to be correct or true; he views it as a kind of benign myth; (4) the specific tasks or procedures prescribed by the theory. These tasks, in his view, may not function in the ways the theory depicts (since, after all, many different kinds of tasks and procedures seem to have equivalent efficacy) but rather serve to interact with the prior three factors to help the patient overcome demoralization and to mobilize the patient to initiate changes in his or her life.

Later, Goldfried (e.g., Goldfried 1980; Eubanks and Goldfried 2019), another influential proponent of common factors (or, as he later emphasized, common principles of change) built upon Frank's work and other research by himself and others and suggested that the common factors underlying therapeutic efficacy across orientations were (1) fostering hope, positive expectations, and motivation; (2) facilitating the therapeutic alliance; (3) increasing the patient's awareness and insight; (4) encouraging corrective experiences; and (5) emphasizing ongoing reality testing.

Perhaps the most elaborated and influential framing of the common factors approach has been offered by Wampold (e.g., Wampold and Imel 2015). In his model, which builds on the pioneering work of Frank but elaborates and refines it on the basis of an enormous body of empirical research, three main pathways to change account for the common efficacy of varied therapeutic approaches. First is the therapeutic relationship, a factor in therapeutic change that consistently is found to account for more of the variance than any specific technique or theory (Norcross and Lambert 2019; Norcross and Wampold 2019). Second is the creation of positive expectations. In part, this dimension includes the powerful set of psychological processes that are referred to as placebo effects when they are compared to physical or chemical influences in medicine or are embodied in a "control group" in psychotherapy research but that are also, as Wampold reminds us, at the very heart of what generates change in psychotherapy. These expectations, however, as Wampold describes, do not function simply as cures by suggestion but as factors that mobilize the patient to engage in a range of therapeutic tasks and new actions that can genuinely change his or her life. Here, the third factor, the specific interventions and procedures of any particular therapeutic model completes Wampold's account. $\mathrm{He}$ is attentive to the evidence supporting many of these specific interventions, but argues that their efficacy (and the efficacy of quite different procedures and interventions) must be understood contextually. Ultimately, for Wampold, "the scientific validity of the explanation of distress and the therapeutic actions is not what is important; rather it is the client's acceptance and engagement in these aspects that is needed. That is, the explanations must be credible to the patient... focusing on the client's problem, providing an explanation for the problem, and instituting specific therapeutic actions ... seem to render the treatments more effective." (Wampold and Ulvenes 2019, p. 76).

This latter statement indicates that Wampold's and other common factors models, although giving a place to the specific interventions of particular therapeutic models, ultimately reduces them to interchangeable elements that serve to motivate or convince the patient or client rather than genuinely specific and independently meaningful sources of therapeutic change beyond the client's believing in them. The third approach to integration depicted by Arkowitz, theoretical integration takes those specific factors more seriously. This approach essentially addresses the same ("Dodo bird") findings at the core of the common factors approach and attributes them to different therapies mobilizing different therapeutic processes. ${ }^{1}$ It thus holds out the hope of a still more effective treatment by combining those different genuinely therapeutic processes (e.g., Wachtel 1997). Critical to this effort being coherent, rather than an ugly mixture of incompatible elements, is the development of a theoretical framework that aims to encompass the observations deriving from two or more orientations that had been previously siloed. Those siloes, which serve as serious obstacles to learning from both the successes and failures of other approaches, and are reinforced by partisan attitudes both of negativity toward other orientations and exaggerated confidence in the sufficiency of one's own, are also reinforced by the different language that therapists of different orientations use for what are often very similar phenomena. Practitioners of theoretical integration generally both translate terms from one framework to another in order to illuminate the convergences that different jargons obscure and develop new terms or new meanings for old terms in order to conceptualize a broader swath of behavioral and experiential reality.

A fourth prominent approach to psychotherapy integration that was not included in Arkowitz's original taxonomy is that of assimilative integration (e.g., Messer 1992; Stricker and Gold 2019). This approach can be seen as a variant (or refinement) of theoretical integration, since it is not simply eclectic in the sense of atheoretical empiricism and does not, like the common factors approach, essentially assume that

\footnotetext{
1 Advocates of theoretical integration do not dismiss common factors as also contributing in important ways. But they view those common factors as only part of what is important in each of the major approaches and seek to combine specific and common factors for a more comprehensive therapeutic effort.
} 
the same therapeutic elements power each of the separate orientations. Instead, like theoretical integration, it seeks to put together the different therapeutic agents that characterize each of the separate orientations and to do so in a theoretically coherent fashion. But the assimilative integration approach emphasizes that no effort at theoretical integration starts out in a "virginal" manner. All proponents of integration start from somewhere, and how they look at the end is in good part shaped by where they started. Assimilative integrationists argue that no theorist or therapist can observe all there is to observe in an Olympian or thoroughly evenhanded fashion. They filter what they notice, interpret what passes through the filter, and organize those observations and the theorizing they generate from the vantage point of already existing schemas. But unlike the true believers who reside strictly within the silos of one orientation or another, practitioners of assimilative integration are open to, indeed eagerly interested in, the observations and clinical methods of therapists who differ from the orientation in which they were originally trained. They thus actively assimilate these new observations, ideas, and methods into the framework from which they began, and in the process that framework changes, evolves, and expands.

Most of the papers in this special issue, in one way or another, are part of these latter two dimensions of psychotherapy integration. Wakefield, Baer, and Conrad offer a particularly broad range of perspectives in making their case for integration as the only sound and responsible course for the clinician. They root their argument equally in empirical, theoretical, and ethical considerations. From an empirical vantage point, they highlight a large body of data, usually underplayed or "spun" by proponents of one orientation or another, that suggests that no single orientation is really sufficient to meet the needs of the variety of patients or clients who seek our help and that in a very large number of cases, even when treatment is presented in reporting the outcome of studies as successful, it in fact often leaves many of the "successful" clients far from fully resolved in their distress or able to resume their lives with full vitality and richness. They complement this analysis of the empirical data with a rich web of theoretical and ethical arguments that point in the same direction.

Eagle's integrative argument is in some ways narrower. His focus is primarily on the integration of the competing schools within psychoanalysis. But his paper is a model of careful analysis and reasoning, attentive to both theory and empirical findings, that is a prime example of the integrative mindset at its best. Along the way, he introduces critical challenges to the diagnostic scheme that is so powerfully shaped by the medical model and the checklist approach of hospitals and insurance companies, more suited to matters of billing than understanding patients' or clients' needs. The integrative conception of psychopathology that anchors his arguments introduces considerations whose relevance extends well beyond the realm of psychoanalysis alone.

The papers by Lane, Levenson, and Ecker and Bridges form an intersecting triad of reflections on the role of emotions and neural processes in the conduct and experience of psychotherapy. In her paper on Time Limited Dynamic Psychotherapy (TLDP), Levenson offers an integration of traditional psychodynamic therapy and emotion-focused therapy. Rich with clinical illustrations, the paper illustrates how accessing feelings in the here-and-now can contribute to transforming old dysfunctional patterns of relating to self and others. She clarifies an important point that has often been left ambiguous in psychodynamic writing and has thereby impeded progress - that although psychodynamic therapy has been centrally concerned with affect from its very beginnings, the predominantly interpretive emphasis of much psychodynamic work has cast that interest in affect into a largely cognitive, and sometimes even intellectualized, activity, notwithstanding the declared focus on affect. In contrast, the way of working Levenson describes capitalizes on more than a century's work in illuminating the nature and content of the affective conflicts that therapy needs to address, but does so in a more affectively immediate manner.

Lane similarly explores the interface between psychodynamic therapy and emotion-focused therapy, with a particular emphasis on including knowledge gained from affect science and neuroscience in the integrative model. He explores differences between the two visions of therapy and presents a bridging framework grounded in neurobiology to reconcile them and coherently take the best from both. Of particular importance in this evolving model is recent research on the reconsolidation of emotional memories, and Lane offers a three-part conceptualization of the processes that maximize the likelihood of deep and enduring change. The first is activating old memories and experiencing the painful emotions (often previously defended against) that are associated with those memories. Second is the occurrence of corrective emotional experiences that challenge and alter the memory associations. Third, and very important, is the consolidating of this change process by extending it into the person's daily life and encouraging and promoting new ways of behaving and experiencing that can generate new experiences and new memories consistent with the changes the therapy has brought about.

Ecker and Bridges too center their therapeutic vision on the findings of neuroscientists regarding the process of memory reconsolidation. In their paper, they make a distinction between incremental change and transformational change. Their claims are large, and different readers will evaluate them differently. But importantly, they acknowledge that when what they call transformational change occurs, it is not the exclusive property of any particular "system" of psychotherapy but can occur across a wide range of approaches 
if the proper conditions are met. Theirs is a challenging and ambitious paper, and it pushes us to consider further both the foundations of successful therapy and how those foundations can be manifested across the boundaries that currently divide our field into separate therapeutic fiefdoms.

The next three papers in the issue extend the focus from the individual to couples and systems. Fishbane, Siegel, and Goldman, illustrate three established models of couple treatment that focus on emotion in understanding the issues that bring couples into therapy. Each author provides an overview of the approach they are identified with, accompanied with an illustrative case example. Although the premise regarding the change process differs, all three models pay attention to dyadic interactions, emotions, and the power of the past that contribute to the impasses that couples often struggle with. As the authors agreed on the benefits and potential for integration in advancing the field of couple therapy, Arthur Nielsen was invited to write a commentary elaborating on the ways these models can advance our appreciation for an integrated approach. It is interesting to observe how clinical approaches that have developed from different conceptual origins arrive at positions that are in many ways similar. As Nielson observes, the ability to interweave attention to interpersonal as well as intrapsychic processes allows for more flexibility and responsiveness to the couple's concerns.

Finally, further expanding the reach and the modalities of integration, Fraenkel's paper on integrating music into work in couples therapy adds a dimension of integrative focus that is rarely considered but, as Frankel powerfully argues, is a powerful element in forging a fully comprehensive human perspective on psychotherapy. Frankel cites a good deal of rigorous scientific research, especially in the realm of neuroscience, but argues that science alone can never be sufficient for a fully comprehensive and integrative approach. Complementing science in the highest human achievements, the arts and humanities also represent both how we understand the world and how we exercise our powers as reflective, conscious, creative beings. His case for the role of music in couples therapy certainly has applications to work with individuals as well. Moreover, even apart from the explicit and conscious introduction of music into the work, Fraenkel illuminates the ways in which music-tone, timbre, volume, tempo, etc.-is always a part of therapy and makes it clear that attention to these dimensions of the therapeutic interaction is a critical element in maximizing the therapist's ability to address fully what is going on in the room.

Frankel's call for a synthesis of science, craft, and art can be seen as in some way the grounding of all of the papers in this series and of psychotherapy integration more generally. From the rich cornucopia of papers in this special issue, the reader can gain an excellent brief introduction to the diversity of viewpoints and strategies that constitutes the contemporary psychotherapy integration movement. We invite you to immerse yourself in these papers, to examine them, absorb them, debate them, and, in the true spirit of SEPI, to engage in dialogue with them. The authors will be glad to hear your thoughts, reactions, objections, questions - and ways in which the papers have altered your ways of understanding and working with clients. If you would like to learn more about the wide range of ways in which therapists of varied orientations are attempting to expand the boundaries of their practices beyond their original training and about opportunities to stay abreast of these developments and engage in dialogue with fellow open-minded and creative therapists, you can visit the SEPI website at www. sepiweb.org. We are eager to add clinical social workers to the existing SEPI family in the hope that the spirit of integration and exchange can inform the practices of the largest numbers of mental health and family therapy providers.

\section{References}

Arkowitz, H. (1984). Historical perspective on the integration of psychoanalytic therapy and behavior therapy. In H. Arkowitz \& S. M. Messer (Eds.), Psychoanalytic therapy and behavior therapy: Is integration possible? (pp. 1-30). New York: Plenum.

Arkowitz. H. (1997). Integrative theories of therapy. In P. L. Wachtel \& S. M. Messer (Eds.), Theories of psychotherapy: Origins and evolution (pp. 227-288).

Beutler, L. E. (1983). Eclectic psychotherapy: A systematic approach. New York: Pergamon.

Consoli, A. J., \& Beutler, L. E. (2019). Systematic treatment selection. In J. C. Norcross \& M. R. Goldfried (Eds.), Handbook of psychotherapy integration (3rd ed., pp. 141-157). New York: Oxford University Press.

Eubanks, C. F., \& Goldfried, M. R. (2019). A principle-based approach to psychotherapy integration. In J. C. Norcross \& M. R. Goldfried (Eds.), Handbook of psychotherapy integration (3rd ed., pp. 88-104). New York: Oxford University Press.

Frank, J. D. (1961). Persuasion and healing: a comparative study of psychotherapy. Baltimore, MD: Johns Hopkins Press.

Goldfried, M. R. (1980). Toward the delineation of therapeutic change principles. American Psychologist, 11, 991-999.

Lazarus, A. A. (1989). Why I am an eclectic (not an integrationist). British Journal of Guidance \& Counseling, 17, 248-258.

Lazarus, C. N., \& Lazarus, A. A. (2019). Multi modal therapy. In J. C. Norcross \& M. R. Goldfried (Eds.), Handbook of psychotherapy integration (3rd ed., pp. 125-140). New York: Oxford University Press.

Messer, S. M. (1992). A critical examination of belief structures in integrative and eclectic psychotherapies. In J. C. Norcross \& M. R. Goldfried (Eds.), Handbook of psychotherapy integration (3rd ed., pp. 130-168). New York: Basic Books.

Norcross, J. C., \& Lambert, M. J. (2019). Psychotherapy relationships that work. Vol. 1: Evidence-based therapist contributions. New York: Oxford University Press.

Norcross, J. C., \& Wampold, B. E. (2019). Psychotherapy relationships that work. Vol. 2: Evidence-based therapist responsiveness. New York: Oxford University Press.

Rosenzweig, S. (1936). Some implicit diverse factors in diverse methods of psychotherapy. American Journal of Orthopsychiatry, 6, 412-415. 
Stricker, G., \& Gold, J. (2019). Assimilative psychodynamic psychotherapy. In J. C. Norcross \& M. R. Goldfried (Eds.), Handbook of psychotherapy integration (3rd ed., pp. 207-227). New York: Oxford University Press.

Wachtel, P. L. (1997). Psychoanalysis, behavior therapy, and the relational world. Washington, DC: American Psychological Association.

Wampold, B. E., \& Imel, Z. E. (2015). The great psychotherapy debate: The research evidence for what works in psychotherapy (2nd ed.). New York: Routledge.
Wampold, B. E., \& Ulvales, P. G. (2019). Integration of common factors and specific ingredients. In J. C. Norcross \& M. R. Goldfried (Eds.), Handbook of psychotherapy integration (3rd ed., pp. 69-87). New York: Oxford University Press.

Publisher's Note Springer Nature remains neutral with regard to jurisdictional claims in published maps and institutional affiliations. 